\title{
US and Europe set to clash over emissions
}

[WASHINGTON] Conflict between Europe and the United States over the use of emissions trading to meet targets for cuts in carbon emissions is set to overshadow the opening this week of the fourth Conference of the Parties to the International Framework Convention on Climate Change in Buenos Aires.

The European Union will seek to place restrictions on the extent to which nations can rely on trading to achieve the cuts they agreed to at the last conference in Kyoto, Japan. It has been encouraged in this by environmental groups that believe the United States wants to use emissions trade with Russia and developing countries to avoid any significant cuts to its own emissions.

The meeting of 175 countries in Argentina, which began on 2 November, will try to agree on a timetable for resolving how emissions trading should work, as well as other critical details of the protocol agreed at Kyoto last December. These include the treatment of carbon 'sinks', the proposed Clean Development Mechanism to help control emissions in developing countries, and compliance mechanisms to enforce the protocol.

But none of these issues will be settled at Buenos Aires, where protagonists are expected instead to argue about the timetable for their settlement. Some nations will push for a strict timetable, with most of the points of contention being resolved by the sixth conference of the parties, due to take place in 2000 or 2001.

The developing countries, led by China and India and represented by the so-called Group of 77 (G77), are expected to use their voting power to knock the issue of setting fixed emission targets off the agenda at the meeting. The US delegation will try to get it reinstated, but there is no expectation of any significant movement towards such targets for developing countries.

Instead, the United States and its allies are looking to Carlos Menem, the Argentinian president, to provide a semblance of progress on the issue by promising further voluntary cuts in emissions by Argentina when he addresses the conference.

Late last week, the Clinton administration was still to decide whether $\mathrm{Al}$ Gore, the vice-president, would go to the meeting. Environmental groups were hoping that Gore would not only attend but would also sign the Kyoto Protocol. This would be a largely symbolic gesture, however, since there is no prospect of Clinton submitting the measure for the necessary ratification by the US Senate.

But in the run up to Buenos Aires, there has been some indication of reduced hostility in the Senate to cuts in US carbon emissions. Last month, Senator Connie Mack (Republican, Florida) co-sponsored a bill to give corporations credits for emissions cuts they make now, in advance of any future cuts required to meet the Kyoto targets. This tacit admission by an influential, conservative Republican senator that domestic emissions need to be cut has greatly encouraged supporters of the Kyoto treaty in the United States.

"Senator Mack's action is very significant," says Senator Joe Lieberman (Democrat, Connecticut), a co-sponsor of the measure and a supporter of emissions cuts, who will attend the Buenos Aires meeting. "We're on the right side of history here."

Initiatives to limit emissions "can be frustrated for a short period of time", he adds, predicting that recent announcements by corporations planning to cut their own emissions are "going to wear down opposition to action on climate change".

Last week, a coalition of the companies BP, General Motors and Monsanto, and the World Resources Institute released a report suggesting extensive, voluntary, precautionary action to measure and reduce emissions.

But some environmental groups continue to doubt the intentions of both international corporations and the US delegation at

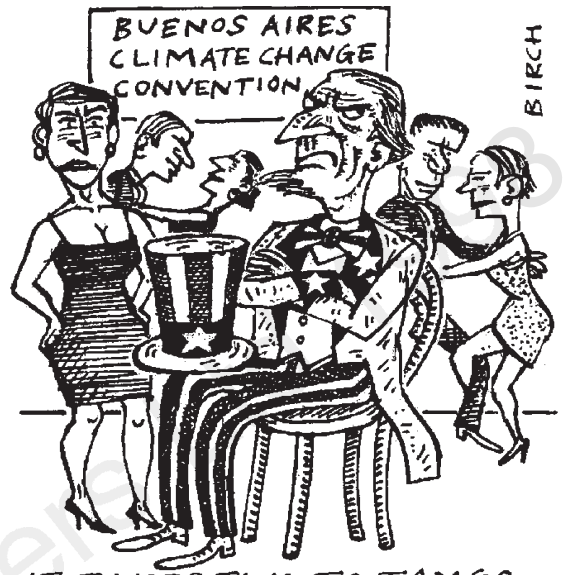

IT TAKES TWO TO TANGO...

the Buenos Aires meeting. The United States "is trying every possible means to [avoid] domestic cuts in emissions - and the Europeans are the most powerful folks in their way," says Kalee Krieder, a climate change specialist at Greenpeace.

Dan Lashof of the National Resources Defense Council, another environmental group, argues that "the United States should reassure other governments of our commitment, and outline steps to begin real emissions reductions at home". ColinMacilwain

\section{Recalcitrant institutes face cuts in Japan}

[токуо] Japanese ministries and agencies that do not cooperate with the government's planned administrative reform, including the restructuring of national research institutes and universities, could open such organizations to substantial budget cuts in the next fiscal year as a penalty.

This warning was delivered last week by Hiromu Nonaka, the chief cabinet secretary, in announcing the details of the interim report on administrative reform, which includes recommendations to transform government-run organizations into semiautonomous bodies.

The reform plan has met strong opposition from ministries and agencies. In particular, national research institutes and universities have shown concern about the effect of such reorganization on the quality of their research (see Nature 395, 730; 1998). The interim report also describes their concerns over the difficulty of transforming all the targeted organizations into new corporations with administrative independence.

Frustrated by the ministries' lack of enthusiasm for implementing the plan, Keizo Obuchi, Japan's prime minister, has now told the Management and Coordination Agency to take firm action against institutions resisting the reform plan by imposing a 30 per cent cut on their budgets for the fiscal year 1999, which begins next April.

"At the moment, there is no feeling of enthusiasm among ministries and agencies to carry out a drastic reorganization of their administrative systems," Nonaka said at a press conference last week. "It is therefore necessary to take strong action in order to push through with the planned reform."

The administrative reform plan is also starting to attract criticism from within the ruling Liberal Democratic Party (LDP). Some LDP politicians, including those involved in administrative reform, are calling for the plan to be postponed so they can prioritize plans to improve the nation's ailing economy.

At a party meeting last week, members of the LDP's administrative reform committee expressed concern about the lack of progress in plans to revive the Japanese economy, arguing that too much effort has been spent on the planned restructuring of government ministries and agencies.

The government hopes to finalize its reorganization plans by next January, but many are predicting considerable delays in the wake of the criticisms of Obuchi's reform efforts.

Asako Saegusa 